\title{
Elevated Temperature Wear Behavior of Thermally Sprayed WC-Co/Nanodiamond Composite Coatings
}

\author{
Andy Nieto ${ }^{\mathrm{a}, \mathrm{b}}$, Jaekang Kim ${ }^{\mathrm{b}, \mathrm{c}}$, Oleksiy V. Penkov ${ }^{\mathrm{b}}$, \\ Dae-Eun Kim ${ }^{\mathrm{b}, \mathrm{c}^{*}}$, Julie M. Schoenung ${ }^{\mathrm{a}, \mathrm{d}^{*}}$ \\ ${ }^{a}$ Department of Chemical Engineering and Materials Science, \\ University of California Davis, Davis, CA, 95616, USA \\ ${ }^{b}$ Center for Nano-Wear, \\ Yonsei University, Seoul 120-749, Republic of Korea \\ ${ }^{\mathbf{c}}$ Department of Mechanical Engineering, \\ Yonsei University, Seoul 120-749, Republic of Korea \\ d Department of Chemical Engineering and Materials Science, \\ University of California Irvine, Irvine, CA, 92697, USA
}

\begin{abstract}
This study investigates the effects of nanodiamonds (ND) on the wear behavior of WC-Co coatings during dry sliding under ambient and elevated temperature environments. The nanometric dimensions and exceptional hardness of ND are envisioned to enhance hardness while maintaining toughness, thereby enhancing wear resistance. ND reinforced WC-Co coatings were successfully fabricated by high velocity oxygen fuel spray (HVOF) and air plasma spraying (APS). The tribological behavior of WC-Co-ND composite coatings was evaluated at room temperature and at $300{ }^{\circ} \mathrm{C}$ using reciprocating dry sliding wear tests. At room temperature, the addition of ND led to an enhancement in wear resistance of $8.5 \%$ and $13 \%$ in HVOF and APS coatings, respectively. The composite coatings exhibited increased formation of a protective silica tribolayer, which was attributed to enhanced heat transfer induced by the excellent thermal conductivity of diamond. At $300{ }^{\circ} \mathrm{C}$, however, the composite coatings exhibited poorer wear resistance than the counterpart WC-Co coatings as a result of the degradation of the ND phase. The loss of the diamond phase was believed to decrease hardness and weaken splat interfaces, which led to more facile delamination in HVOF coatings, as well as severe brittle wear and fracture in APS coatings.
\end{abstract}

Keywords: Nanodiamond, Wear, Thermal Spray, Nanocomposite, Cermets

*Corresponding author: Email:Julie.Schoenung@UCI.edu; Phone: 949-824-2575

Email: kimde@yonsei.ac.kr , Phone: 02-2123-2822 


\subsection{INTRODUCTION}

Carbonaceous nanomaterials have garnered significant attention as reinforcements for polymer [1-4], metal [5-7], and ceramic matrix composites [8-10] due to their excellent mechanical and functional properties. Recently, nanodiamonds (ND) have attracted interest due to their retention of the excellent mechanical and thermal properties of bulk diamond, while possessing an appealing high chemical activity due to their exceptionally high relative surface area [11-14]. In addition, unlike many nanomaterials, ND represent an economic and environmentally friendly alternative due to their synthesis via the detonation/explosion method $[12,15,17]$. ND are synthesized by carefully controlling the detonation of carbon based and oxygen depleted explosives (e.g., TNT) in order to yield conditions that are thermodynamically favorable for the nucleation of nano-sized diamond particles $[12,17$, 18]. A few studies have recently incorporated ND into metal matrix composites and have demonstrated that ND enhanced the thermal conductivity [19], hardness [19 - 27], elastic modulus [24], and wear resistance [19, 23, 27] of the composite materials. ND have also demonstrated remarkable stability when being processed under aggressive and harsh environments such as those imposed by air plasma spraying [27], cold spraying [24, 26], and hot extrusion [22]. However, previous studies have only explored the use of ND in relatively low melting point materials such as aluminum alloys [19, 23 - 28] and copper alloys [20 22, 29].

ND are proposed here as a reinforcement phase for wear resistant WC-Co coatings. WC-Co coatings are utilized in a variety of machinery applications requiring superb sliding wear resistance due to the combination of high strength and hardness from WC, and the ductility provided by the Co binder. The wear resistance of WC-Co coatings is typically 
increased by increasing the WC content; this, however, leads to a loss in ductility due to the reduced Co content [30]. The addition of ND would be expected to enhance strength and hardness, without any detrimental effects on ductility, benefits commonly observed with many other dispersoid reinforcements [31-33]. The addition of ND is also expected to serve as a source of nano-carbon, which may inhibit decarburization of $\mathrm{WC}$, due to the higher reactivity of nanoparticles. Decarburization is known to be one of the primary degradation mechanisms in WC-Co coatings as it leads to the formation of brittle phases at the expense of the ductile cobalt binder, thereby promoting fracture [30, 34-39]. The addition of graphite to WC-Co coatings can inhibit decarburization [40, 41]; and the addition of other carbon nanomaterials, such as graphene nanoplatelets, has been demonstrated to inhibit the decarburization of other carbides such as $\mathrm{TaC}$ [42].

In the present study, ND reinforced WC-Co coatings were fabricated by high velocity oxygen fuel spray (HVOF) and air plasma spray (APS) and subjected to reciprocating dry sliding wear tests at room temperature and at $300{ }^{\circ} \mathrm{C}$. Dry sliding tests are critical for machinery applications such as pistons, landing gears, and bearings where lossof-lubrication conditions may occur. Dry conditions also enable intrinsic properties of the materials (tribocouples) to be evaluated. Both HVOF and APS coating deposition techniques were utilized here as they are the two most widely employed industrial methods of depositing protective WC-Co coatings. WC-Co coatings are often utilized under elevated temperature environments, typically below $450{ }^{\circ} \mathrm{C}$ [43], and previous studies have demonstrated that wear performance at elevated temperatures is dependent on both the spray deposition technique, as well as the counter-surface employed [43-46]. WC-Co coatings are generally not utilized at temperatures higher than $450{ }^{\circ} \mathrm{C}$ because decarburization occurs 
rapidly and leads to subsequent embrittlement of the coatings. As such, an intermediate temperature of $300{ }^{\circ} \mathrm{C}$, which has been utilized in several previous studies [44-46], is utilized in the present study. The present work is the first to evaluate the wear behavior of a ND reinforced composite at elevated temperature, which is critically important given the inherent instability of nanostructured materials and metastable phases.

\subsection{MATERIALS AND METHODS}

\subsection{Materials}

The starting ND powder was procured from Nanostructured \& Amorphous Materials, Inc. (Synthesized Nanodiamond \#1321JGY, Houston, TX). Nanodiamonds were synthesized by the detonation explosion synthesis method and had a purity of $98 \%$ diamond, as specified by the manufacturer. The ND powder had a specific surface area of $282.2 \mathrm{~m}^{2} / \mathrm{g}$, and the primary impurities included Fe $(0.062 \mathrm{wt} \%)$ and $\mathrm{Si}(0.014 \mathrm{wt} \%)$, and all other impurities were less than $0.01 \%$, as specified by the manufacturer. A previous study

reported the true density of ND powder to be $3.22 \mathrm{~g} / \mathrm{cm}^{3}$, determined using the helium pycnometry technique [27]. The starting thermal spray grade WC-Co powder was procured from Oerlikon Metco (Diamalloy 2004, Wohlen, Switzerland) and had a composition of 88 wt $\%$ tungsten carbide and 12 wt.\% cobalt, which corresponds to a density of $14.82 \mathrm{~g} / \mathrm{cm}^{3}$. Tungsten carbide cobalt nanodiamond (WC-Co-ND) composite powder was synthesized by mixing the starting WC-Co powder with 5 vol.\% ND powder via mechanical milling. Mechanical milling was conducted for 45 min using a stainless steel jar and stainless steel balls, with a ball-to-powder ratio of 0.10 .

\subsection{Coating Synthesis}


WC-Co and WC-Co-ND coatings were deposited using HVOF and APS at Plasma Technologies (Torrance, CA). Coatings were deposited onto 152 x 19 x $3.2 \mathrm{~mm} 1018$ stainless steel substrates, which were grit blasted with alumina particles and cleaned using compressed air and methanol rinsing prior to deposition. HVOF spraying was conducted using a Praxair-TAFA JP5000 (Danbury, CT) thermal spray gun operated with a kerosene based fuel and helium as the secondary gas. A standoff distance of $25.4 \mathrm{~cm}$ from the substrate was utilized for HVOF deposition. APS spraying was conducted using a Metco Type 7MC (Wohlen, Switzerland) plasma spray system with an external powder feed gun operating at a voltage of $68 \mathrm{~V}$ and a current of $713 \mathrm{~A}$. Argon gas flowing at a pressure of $\sim 620 \mathrm{kPa}$ was used as the primary gas, and helium flowing at a pressure of $\sim 655 \mathrm{kPa}$ was used as the secondary gas. A standoff distance of $15.2 \mathrm{~cm}$ from the substrate was utilized for APS deposition. Substrates were preheated to $\sim 250{ }^{\circ} \mathrm{C}$ and actively cooled during the deposition processes using cooling air jets on the backside of the substrate. Coatings were deposited to a thickness of $150-200 \mu \mathrm{m}$ using both thermal spray methods. These deposition conditions were chosen on the basis of best-practice parameters used by Plasma Technologies for the fabrication of commercial WC-Co coatings.

\subsection{Structural and Chemical Characterization}

The starting ND powders were characterized by transmission electron microscopy (TEM) using a JEOL 2500 TEM operating at $200 \mathrm{keV}$ in order to assess the size of the ND particles. ND powders were dispersed into a methanol solution via ultrasonication and then a drop of the dispersion medium was deposited onto a lacy carbon TEM grid. An FEI NanoSEM scanning electron microscope (SEM) was utilized to characterize the powders, coating microstructures, and wear track morphologies. All images were taken using the 
secondary electron (SE) mode. Coating porosity and carbide sizes were analyzed using Image J software. Reported ‘error' bars represent one standard deviation, and are indicative of the distribution of material properties. Energy dispersive spectroscopy (EDS) analysis was conducted on an FEI Scios dual-beam focused ion beam - scanning electron microscope (FIB-SEM) equipped with an Oxford EDS system in order to characterize the elemental composition of phases present on coating wear tracks. Phases in the as-sprayed coatings and coating wear tracks were analyzed using a Scintag XDS2000 X-ray diffractometer. The operating voltage and current were $45 \mathrm{kV}$ and $40 \mathrm{~mA}$, respectively. Surface chemistry of the as-sprayed coatings and corresponding wear tracks was analyzed via X-ray photoelectron spectroscopy (XPS) using a Thermo Scientific K-alpha XPS.

\subsection{Mechanical and Tribological Characterization}

Macro-scale reciprocating dry sliding wear tests were conducted using a NeoPlus RFW-160 (Daejeon, South Korea) high temperature tribometer in order to assess the coefficient of friction $(\mathrm{CoF})$ and wear resistance of the coatings. Silicon nitride balls with a diameter of $5 \mathrm{~mm}$ were used as the counter surface; a new ball was used for each test. $\mathrm{Si}_{3} \mathrm{~N}_{4}$ was used as the counter surface because it is harder than WC-Co, is one of the most widely utilized industrial ceramics, and has been used in many studies on WC-Co coatings [30, 43, 46]. The wear tests were run for 60 min utilizing a normal load of $100 \mathrm{~N}$, a stroke length of $5 \mathrm{~mm}$, and a frequency of $2 \mathrm{~Hz}$. This corresponds to 7200 cycles and a total sliding distance of $72 \mathrm{~m}$. Wear tests were conducted at room temperature (RT, $\sim 25{ }^{\circ} \mathrm{C}$ ) and elevated temperature $\left(300^{\circ} \mathrm{C}\right)$. Coatings were lightly polished with $\mathrm{SiC}$ abrasive paper prior to wear tests. After the light polish, HVOF coatings had a roughness $\left(\mathrm{R}_{\mathrm{a}}\right)$ of $\sim 2.4-2.9 \mu \mathrm{m}$, and APS coatings had a roughness $\left(\mathrm{R}_{\mathrm{a}}\right)$ of $4.1-4.4 \mu \mathrm{m}$. The depth and volume profiles of the wear 
tracks were obtained using a Keyence VK-X200 (Osaka, Japan) 3D laser microscope in order to measure the wear volume and thereby gauge the wear resistance of the coatings. Wear volume was obtained by calculating the average wear track cross sectional area of over 100 cross sections, and then multiplying it by the stroke length. Reported wear volumes and CoF values are averages derived from at least three wear tests. The HVOF and APS assprayed coatings, as well as coatings post-300 ${ }^{\circ} \mathrm{C}$ wear tests, were cross-sectioned and mounted. Mounted cross sections were ground using progressively finer silicon carbide abrasive papers, down to a grit size of 600 ; and then polished using progressively finer diamond slurries, with the final polishing step utilizing a slurry with $0.25 \mu \mathrm{m}$ diamond particles. Microindentation was performed on the polished cross sections using a Buehler Micromet 2005 microhardness tester. A standard Vickers tip was used and the loading conditions consisted of a $1 \mathrm{~kg}$ load with a $15 \mathrm{~s}$ dwell. The mean of 15 microindentation tests is reported and 'error' bars represent one standard deviation, and are representative of the variation in material properties, and hence not a measure of experimental error.

\subsection{RESULTS AND DISCUSSION}

\subsection{Composite Powder Characterization}



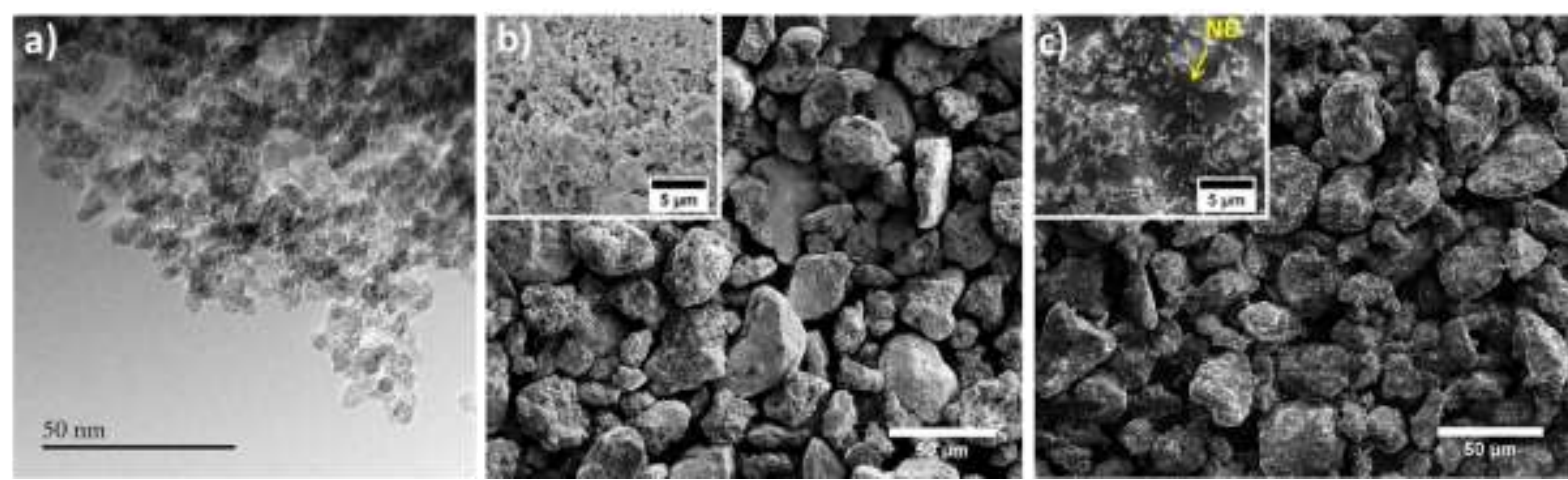

Figure 1: a) Transmission electron micrograph of nanodiamond (ND) powder, b) Scanning electron micrograph (SE) of WC-Co powder. Inset: high magnification of WCCo powder showing submicron size carbides, c) Scanning electron micrograph of WC-CoND powder. Inset: high magnification image showing most of particles are covered with nanodiamond powder, which is distinguished by its low Z-contrast.

The morphology of the as-received ND powder, (Fig. 1a), illustrates that the individual ND particles had diameters of $~ 4-6 \mathrm{~nm}$. The powders, however, were heavily agglomerated in their as-received state; agglomerates on the order of $>100 \mathrm{~nm}$ in diameter containing hundreds of individual particles were observed. The WC-Co thermal spray powder (Fig. 1b) was synthesized through sintering and crushing steps. The spherical WCCo agglomerates were in the range of $\sim 20-45 \mu \mathrm{m}$ in order to have the requisite flowability for thermal spray processing. The inset in Fig. 1b shows that the agglomerates consisted of both micron and submicron sized WC particles in the Co binder. The ND and WC-Co powders were balled milled in order to form a composite powder (Fig. 1c). The ND powder is distinguished in the composite powder by its significantly lower $\mathrm{Z}$ contrast; the lower atomic weight of carbon results in fewer secondary electron interactions and hence a dark gray color due to lower electron counts. After ball milling, the ND powder is homogenously distributed throughout the outer surface of the WC-Co agglomerates (Fig. 1c). The ball milling process produced impact and shear forces that brought the ND particles into intimate 
contact with WC-Co particles. The high surface area of nanopowders creates high adhesion forces [47], which enable them to readily stick to the surface of WC-Co agglomerates. The agglomerated WC-Co powder was dense because the powders are sintered (and subsequently crushed) during synthesis, and hence it is not expected that the ND would be able to permeate through the exterior and be present in the interior of the agglomerates. Furthermore, the ball milling process did not have any significant impact on the size or shape of the agglomerated WC-Co powder.

\subsection{Microstructural Characterization}

The HVOF coatings, (Fig. 2), exhibit porosity that is seen throughout the sample in small pockets. APS coatings exhibit higher porosity with larger pores situated at splat boundaries. The higher porosity of the APS coatings can be seen in Table 1. The APS coatings had porosity values of $\sim 24-30 \%$, in contrast to the HVOF samples, which had porosity values of $\sim 13-19 \%$. The high kinetic energy of the HVOF process leads to higher splat deformation, which enables splats to be stacked and built into coatings with minimal porosity between them. The general microstructural features of the HVOF and APS samples did not change significantly with the incorporation of ND. From Table 1, it can also be seen that the incorporation of ND did not affect carbide particle sizes in either the HVOF or APS coatings. 

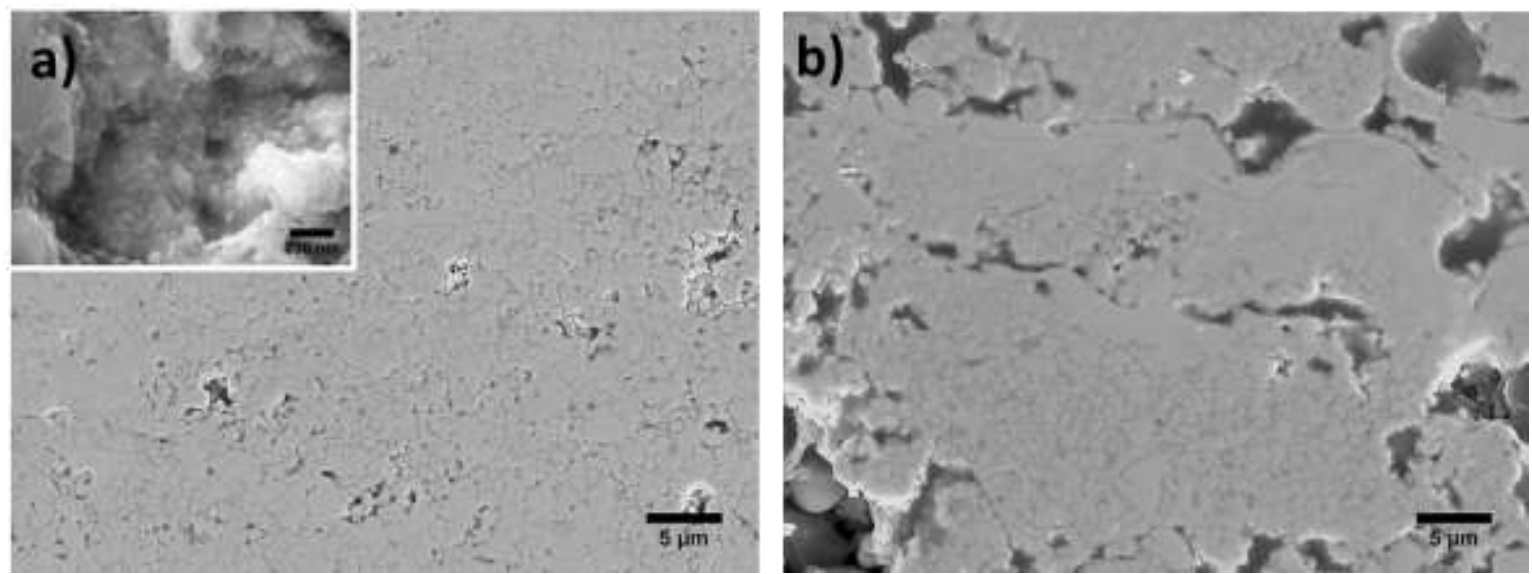

Figure 2: a) SEM (SE) of typical microstructure observed for HVOF coatings. Inset: fine particles seen only in WC-Co-ND samples are believed to be nanodiamonds, b) SEM of typical microstructure observed for plasma sprayed coatings.

Table 1: Microstructural and Mechanical Properties of WC-Co and WC-Co-ND coatings.

\begin{tabular}{|lcccc|} 
Sample & Porosity & Carbide & Hardness $(\mathbf{A S})$ & Hardness $\left(\mathbf{3 0 0}{ }^{\circ} \mathbf{C}\right)$ \\
& $(\boldsymbol{\%})$ & size $(\boldsymbol{\mu m})$ & $(\mathbf{G P a})$ & $(\mathbf{G P a})$ \\
\hline HVOF_WC-Co & $12.8 \pm 1.2$ & $0.62 \pm 0.44$ & $9.7 \pm 0.8$ & $9.7 \pm 0.8$ \\
\hline HVOF_WC-Co- & $18.8 \pm 2.2$ & $0.62 \pm 0.29$ & $9.6 \pm 0.8$ & $9.0 \pm 0.9$ \\
ND & & & & $6.8 \pm 0.9$ \\
\hline APS_WC-Co & $29.8 \pm 4.3$ & $0.73 \pm 0.36$ & $6.4 \pm 0.7$ & $6.4 \pm 0.9$ \\
\hline APS_WC-Co-ND & $24.0 \pm 5.4$ & $0.70 \pm 0.51$ & $6.8 \pm 0.7$ & \\
\hline
\end{tabular}

The effect of ND on porosity varies with the spraying method. In the HVOF coatings, the addition of ND led to ahigher level of porosity, while in the APS samples the addition of ND led to lower porosity. The signature feature of the APS process is the 
extreme temperature that the particles are exposed to, up to $10,000 \mathrm{~K}$ in the initial plasma plume [48]. Such high temperatures result in severe thermal gradients within the powder particles that can result in microstructural alterations. One of the attractive features of diamond is the exceptionally high thermal conductivity of $\sim 2000 \mathrm{~W} \mathrm{~m} \mathrm{~m}^{-1}[49,50]$. Previous studies on Al-ND [19] nanocomposites, as well as previous studies on microdiamond reinforced Al composites [50 - 52], have shown that thermal conductivity is enhanced due to the presence of the conductive diamond phase. It is postulated here that the ND shell on the WC-Co powder particles enhanced heat transfer from the plasma plume to the in-flight powder particles. Increased heat transfer to the powder particles would increase powder temperature and lead to increased splat melting and intersplat bonding, both of which promote densification.

In contrast, the HVOF method utilizes low thermal energy, but high kinetic energy (resulting in denser coatings than those produced by APS), and hence the densification mechanism is mostly deformation driven and solid-state diffusion is necessary to ensure adequate intersplat adhesion and bonding. ND would also be expected to enhance heat transfer during $\mathrm{HVOF}$, but the in-flight time of the particles is much lower compared to APS, due to the supersonic speed of the flame plume, and hence there is minimal time for heat to transfer to in-flight particles [48]. The ND will also inhibit solid-state diffusion as they will act as diffusion barriers, which is the case with other nanoparticles and dispersoids $[53,54]$. The inhibition of diffusion may lead to higher porosity due to reduced intersplat bonding during the deposition process. The effect of ND diffusion inhibition would not be significant in the APS samples, because the powder particles are typically in a 

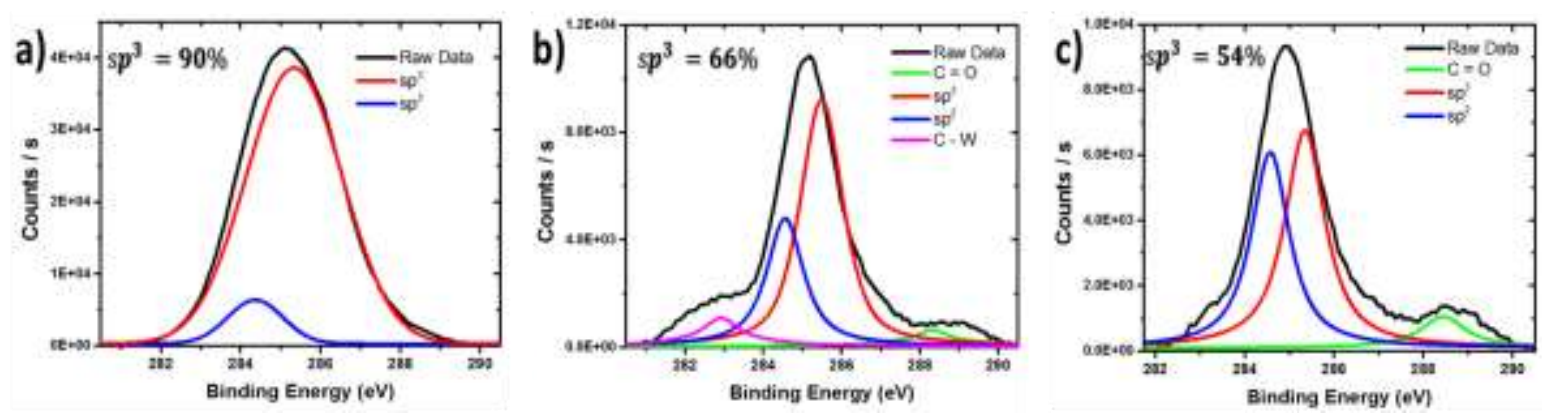

Figure 3: Deconvoluted X-ray photelectron spectra of a) Nanodiamond powder, b) HVOF WC-Co-ND coating, and c) Plasma sprayed WC-Co-ND coating. sp ${ }^{3} \%$ denotes percentage of carbon-carbon bonds that are $\mathrm{sp}^{3}$ in nature.

molten or semi-molten state and hence the bonding process is not dominated by solid-state diffusion [48].

X-Ray photoelectron spectroscopy (XPS), (Fig. 3), was used to assess the effect of the thermal spray processing on the chemical structure of the NDs. Fig. 3a shows that the starting ND powder had $90 \% s p^{3}$ carbon-carbon bonds, which the signature of the diamond structure, and $10 \% s p^{2}$ bonds, which correspond to graphitic carbon. The XPS analysis in Figs. $3 b$ and $3 c$ reveals that the HVOF and APS processing led to a decrease in the percent of $s p^{3}$ bonding from $90 \%$ to $66 \%$ and $54 \%$, respectively. It is expected that the higher temperatures utilized in the APS process lead to a more rapid deterioration of the diamond structure, which is a metastable phase known to undergo graphitization under elevated temperatures above $700{ }^{\circ} \mathrm{C}[55,56]$. XPS analysis confirms that most of the diamond structure is retained during thermal spray processing of WC-Co-ND powders. Indirect evidence of ND in the WC-Co structure is also seen in the inset of Fig. 2a. Fine particles, ranging in size from 20-30 nm, are seen in the HVOF WC-Co-ND coating. These particles are in the size range of the ND agglomerates seen in the starting powders and were not observed in any other coating and hence believed to be ND. 

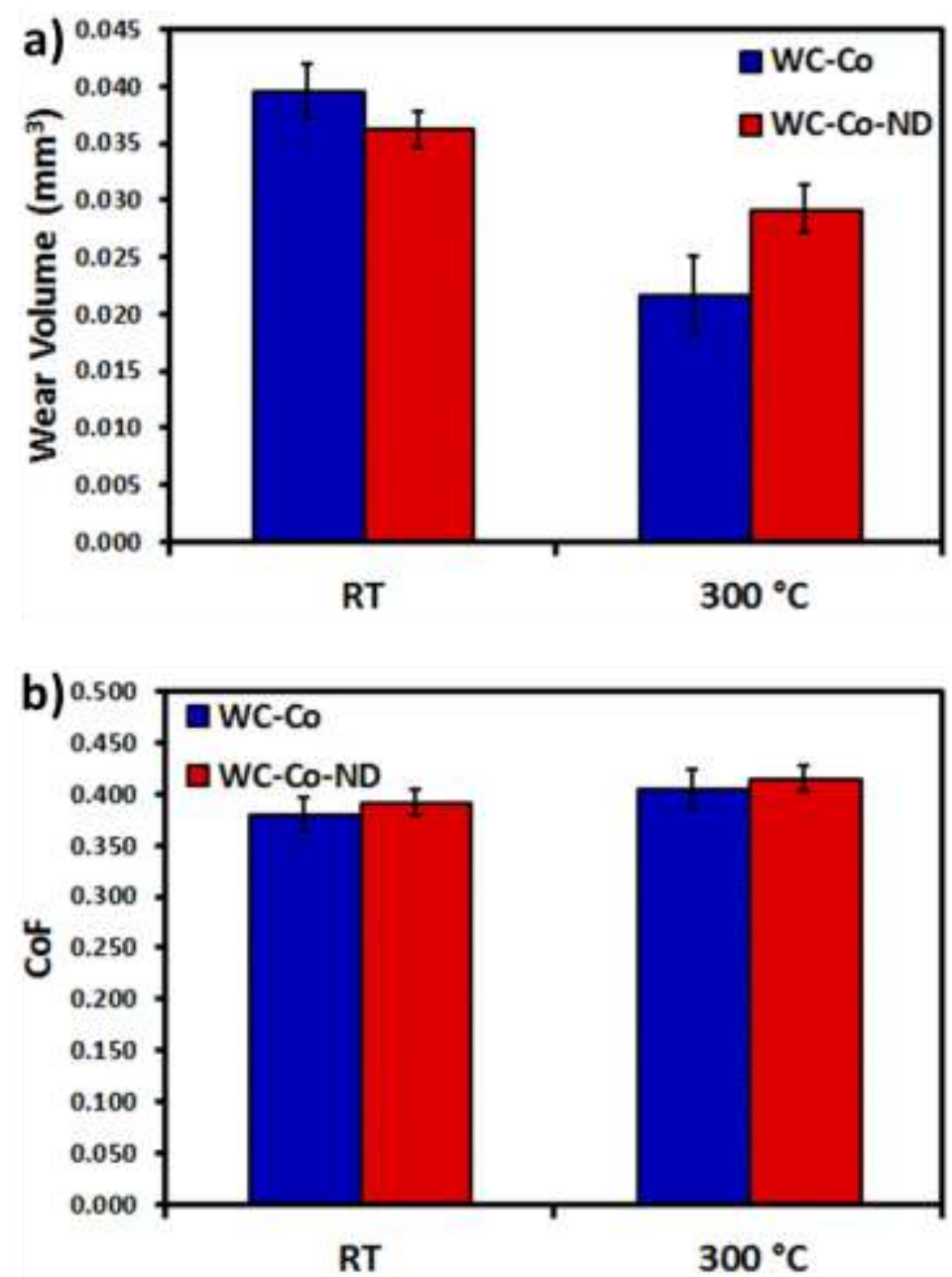

Figure 4: Room temperature and elevated temperature wear study results: a) Wear volume of $\mathrm{HVOF}$ coatings, and b) CoF of HVOF coatings.

\subsection{Wear Behavior of HVOF Coatings}

\subsubsection{Wear Performance and Mechanisms}

The wear performance of the HVOF sprayed WC-Co coatings was characterized by their wear volume and $\mathrm{CoF}$, (Fig. 4). At room temperature (RT), the WC-Co-ND coating had an $8.5 \%$ reduction in wear volume relative to the WC-Co coating, which is a direct measure of enhanced wear resistance. At elevated temperature $\left(300{ }^{\circ} \mathrm{C}\right)$, however, the WCCo-ND had lower wear resistance as evidenced by a wear volume that was $35 \%$ larger than 

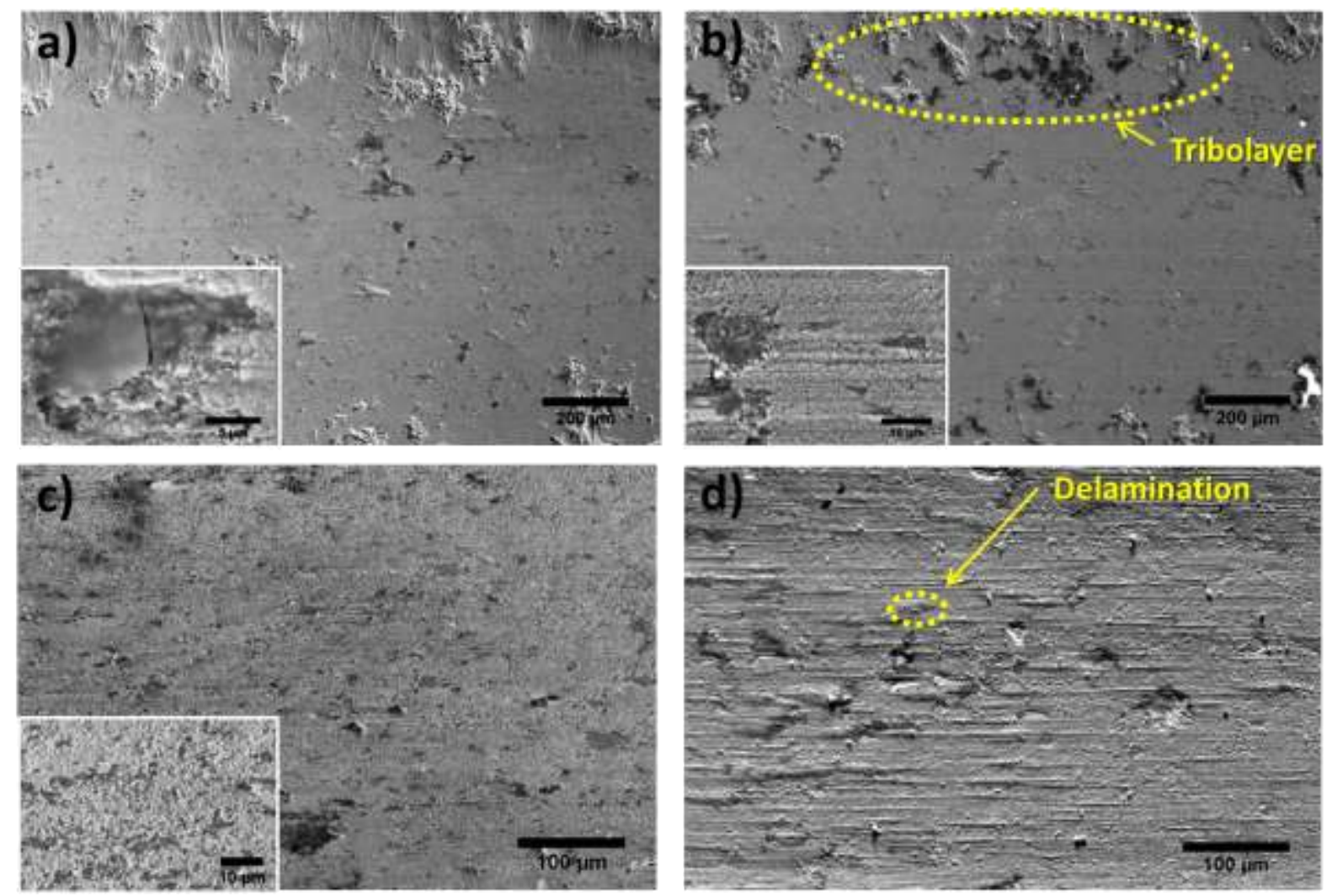

Figure 5: a) SEM (SE) of HVOF WC-Co wear track after RT wear test, Inset: brittle and electron transparent tribolayer formed during wear test, b) SEM of HVOF WC-Co-ND wear track after RT wear test. Significant amounts of tribolayer formed at track edges as indicated in yellow ellipse. Inset: plowing lines indicate wear mechanism is primarily ductile. Regions with pores or cavities are filled with formed tribolayer, c) SEM of HVOF WC-Co wear track after $300{ }^{\circ} C$ wear test. Inset: tribolayer seen throughout surface in between carbide particles, and d) SEM of $\mathrm{HVOF}$ WC-Co-ND wear track after $300{ }^{\circ} \mathrm{C}$ wear test. Increased occurrence of delamination is noted in composite coating at $300{ }^{\circ} \mathrm{C}$.

that of the WC-Co coating. Both coatings had lower wear volumes at $300{ }^{\circ} \mathrm{C}$ than they did at RT. No significant change in CoF was seen with the addition of ND in both test conditions, and the increased temperature only yielded a minor increase in CoF in both coatings.

The wear behavior of these coatings may be understood by examination of the wear track morphology [57], (Fig. 5). The low magnification images in Fig. 5a and b show the relatively smooth wear tracks of WC-Co and WC-Co-ND coatings, respectively, at RT. The wear examination did not reveal any sign of brittle wear. Instead, mild abrasive wear 
behavior was observed, as evidenced by shallow plowing lines throughout the wear track that are not accompanied by either cracking or material pileup. Another prominent feature observed on the coatings was the presence of a smooth and thin tribolayer (inset of Fig. 5a), which was typically found in cavities that were either pre-existing pores or localized delamination induced by the wear test. Tribolayers often contain cracks and are typically electron transparent due to their thinness, and appear as dark patches throughout the wear tracks of both samples. A salient difference between the WC-Co and the composite coating was the formation and accumulation of a significant amount of tribolayer at the edge of the WC-Co-ND wear track, Fig. 5b; the increased formation at the edges was likely due to higher sustained contact pressures at the edges. Flattening of the counter-surface occurs as wear proceeds, reducing the contact pressure at the center of the wear track. Absent any other significant differences, the increased formation of this tribolayer likely dictated the enhanced wear resistance in the composite coating at RT.

At $300{ }^{\circ} \mathrm{C}$, the WC-Co wear track morphology indicated that wear still occurred by mild abrasion. However, a significant increase in tribolayer was observed in the WC-Co coating. Dark patches were seen throughout the track, Fig. 5c. The inset of Fig. 5c indicates that in addition to the patches of tribolayers seen, tribolayer formation was also present at a much finer scale between the carbide particles; this was also the case in the WC-Co-ND sample. These finer tribolayers were not situated at cavities like the tribolayers that form at larger scales, and no signs of cracking are observed on them. Unlike at RT, the WC-Co-ND 

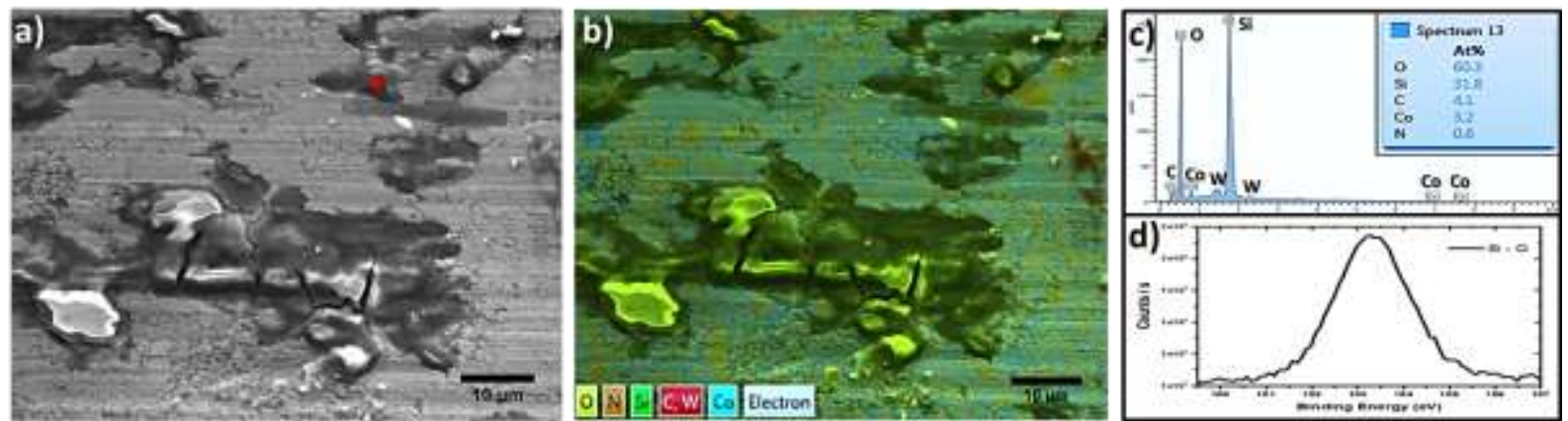

Figure 6: a) SEM (SE) of tribolayer seen on HVOF WC-Co-ND coating's wear track after RT wear test, b) Combined element energy dispersive spectroscopy (EDS) map of SEM image in a) indicating tribolayer is rich in silicon and oxygen. Silicon and tungsten EDS signals partially overlap, c) EDS point quantitative analysis and spectra of tribolayer indicated in image a) by red asterisk, and d) X-ray photoelectron spectra (XPS) of WC-CoND wear track after $300{ }^{\circ} \mathrm{C}$ wear test showing peak at $\sim 105.4 \mathrm{eV}$, which indicates presence of $\mathrm{Si}-\mathrm{O}$ bonds.

coating at $300{ }^{\circ} \mathrm{C}$ had an equivalent or perhaps slightly lower amount of tribolayer formation relative to the WC-Co coating. The level of abrasion in the WC-Co-ND also appeared to be more severe than in the WC-Co coating.

\subsubsection{Phase and Tribolayer Evolution}

The composition of a typical tribolayer seen in a WC-Co-ND coating during RT wear testing is presented in Fig. 6. The typical characteristics of electron transparency and cracking are observed, along with charging at the thicker points of a given tribolayer, thereby indicating that the tribolayer is not conductive. The energy dispersive spectroscopy (EDS) map in Fig. $6 \mathrm{~b}$ reveals that the tribolayer is an oxide. The silicon signal is difficult to discern in the EDS elemental map as $\mathrm{Si}$ and $\mathrm{W}$ have significant overlap in their primary peaks. However, XPS analysis (Fig. 6d) reveals the presence of $\mathrm{Si}-\mathrm{O}$ bonds inside of the wear track. This indicates that the origin of the tribolayers is related to the $\mathrm{Si}_{3} \mathrm{~N}_{4}$ balls used as the counter surface. Previous studies on WC-Co coatings that used $\mathrm{Si}_{3} \mathrm{~N}_{4}$ as the countersurface also reported the formation of a silicon based oxide (silica) during dry sliding wear 
tests [46]. Fig. 6c provides quantitative elemental analysis of the tribofilm; the tungsten signal is masked for the compositional analysis in order to avoid overlap from the atomically heavy tungsten signal. The atomic ratio of silicon to oxygen is approximately $2: 1$, which would be expected for $\mathrm{SiO}_{2}$ (silica). The tribochemical formation of $\mathrm{SiO}_{2}$ is not unexpected as $\mathrm{Si}_{3} \mathrm{~N}_{4}$ readily oxidizes in air at room temperature by the reaction in Eq. (1) [58]:

$\mathrm{Si}_{3} \mathrm{~N}_{4}(\mathrm{~s})+3 \mathrm{O}_{2}(\mathrm{~g}) \rightarrow 3 \mathrm{SiO}_{2}(\mathrm{~s})+2 \mathrm{~N}_{2}(\mathrm{~g}) ; \Delta G_{298 \mathrm{~K}}=-304 \mathrm{kcal} / \mathrm{mol}$

The oxidation reaction would further be promoted by the elevated surface temperatures induced by the frictional heating of the sample due to the continuous rubbing of the tribocouple. Zhao et al. [46] reported the formation of a silica film to be favorable for enhancing wear resistance; the suggested mechanism was that the smooth silica layer acts as a lubricating phase that reduces adhesion and friction. In the present study, no significant decrease in CoF occurred either across compositions or with increased temperature. Instead, it is believed that the silica layer formed acts as a protective layer, rather than a lubricant layer. The silica tribolayers formed at pores or areas of delamination, and hence their presence would decrease the contact stress concentration. Essentially, the tribolayer effectively 'seals' the pores and other cavities with a hard oxide phase. The cracking of the tribolayers demonstrates that they actively participate in the wear process. This cracking phenomenon is favorable as it dissipates energy that would otherwise contribute to wear of the coating, also, the cracks in the tribolayer did not propagate into the surrounding structure.

The increased presence of these protective silica tribolayers on the WC-Co-ND coating, Fig. 5b, is the mechanism responsible for the enhanced wear behavior in the composite coatings. The presence of ND is believed to enhance the formation of the silica 

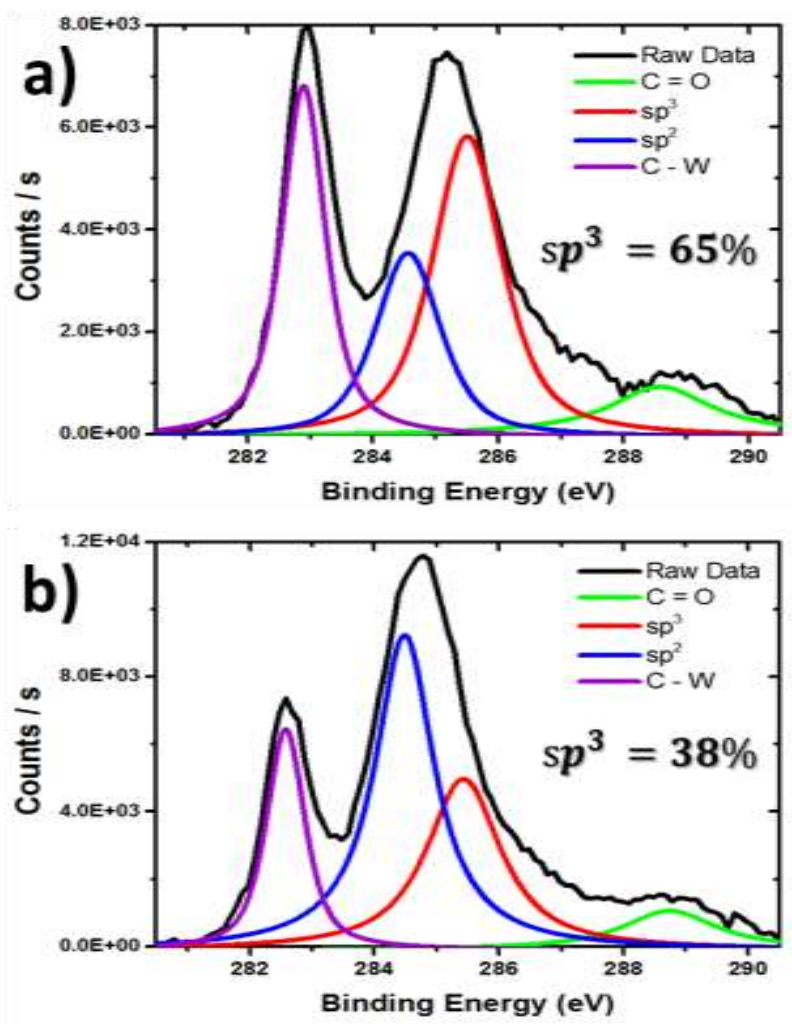

Figure 7: Deconvoluted X-ray photoelectron spectra of a) HVOF WC-Co-ND wear track after RT wear test, and b) $\mathrm{HVOF} W \mathrm{~W}$-Co-ND wear track after $300{ }^{\circ} \mathrm{C}$ wear test. sp ${ }^{3} \%$ denotes percentage of carbon-carbon bonds that are $\mathrm{sp}^{3}$ in nature.

film due to the superb thermal conductivity of ND, which enhanced heat transfer to the coating. The XPS spectra in Fig. 7a show that the RT wear test did not decrease the content of $s p^{3}$ bonded carbon. The retention of the diamond structure after the wear test indicated that the ND phase was stable during wear and can thereby enhance thermal conductivity of the coating and promote increased heat transfer to the coating. The tribolayers were not likely to have been transferred from the counter-surface. Instead, the tribochemical reaction took place on the coating itself, thereby explaining why the tribolayers formed preferentially at high surface area sites such as pores. Being situated at cavities would also enable the reactions to occur uninterrupted by the reciprocating sliding motion, enabling cohesive tribolayers to form, rather than isolated debris. Heat initiated at the tribocouple interface 
must be transferred to either the coating surface, the counter surface, or the surroundings. In summary, the superb thermal conductivity of ND is believed to enhance heat transfer to the coating and thereby further promote the formation of the protective silica tribolayers.

Likewise, at elevated temperatures, the formation of the silica tribolayer was aided by high temperature and heat transfer, which lead to enhanced tribolayer formation and thereby higher wear resistance of the coatings. In order to elucidate the effect of tribolayer formation on the wear behavior at $\mathrm{RT}$ and $300{ }^{\circ} \mathrm{C}$ test conditions, a representative plot of total wear displacement over time is presented for WC-Co in Fig. 8. Total wear displacement is the amount of vertical displacement that the counter-surface ball undergoes during the test, which is an indicator of total system wear, as the counter-surface will shift vertically (down, which is positive displacement) when either the ball or the coating surface becomes worn. The total wear displacement was significantly higher at RT than at $300{ }^{\circ} \mathrm{C}$. The primary feature of interest is the dip in total wear displacement that occurs early on in the test. This negative change in wear displacement indicates that an event occurred that caused the ball to shift upwards. This shift was attributed to the formation of the silica tribolayers on the coating, and possibly some oxide formation on the counter surface ball as well. At $300{ }^{\circ} \mathrm{C}$ the dip was greater than for RT. The larger magnitude of the decrease indicates that the tribolayers formed on the coating and the ball was thicker, possibly due to enhanced chemical reaction, which gave more tribolayer formation at $300{ }^{\circ} \mathrm{C}$. The wear displacement was similar for RT and $300{ }^{\circ} \mathrm{C}$ in the first few minutes of sliding prior to the dip in wear displacement, thereby indicating the enhanced wear resistance at $300{ }^{\circ} \mathrm{C}$ was largely due to tribolayer formation. After the decrease in wear displacement, it continued to increase for both $\mathrm{RT}$ and $300^{\circ} \mathrm{C}$ 


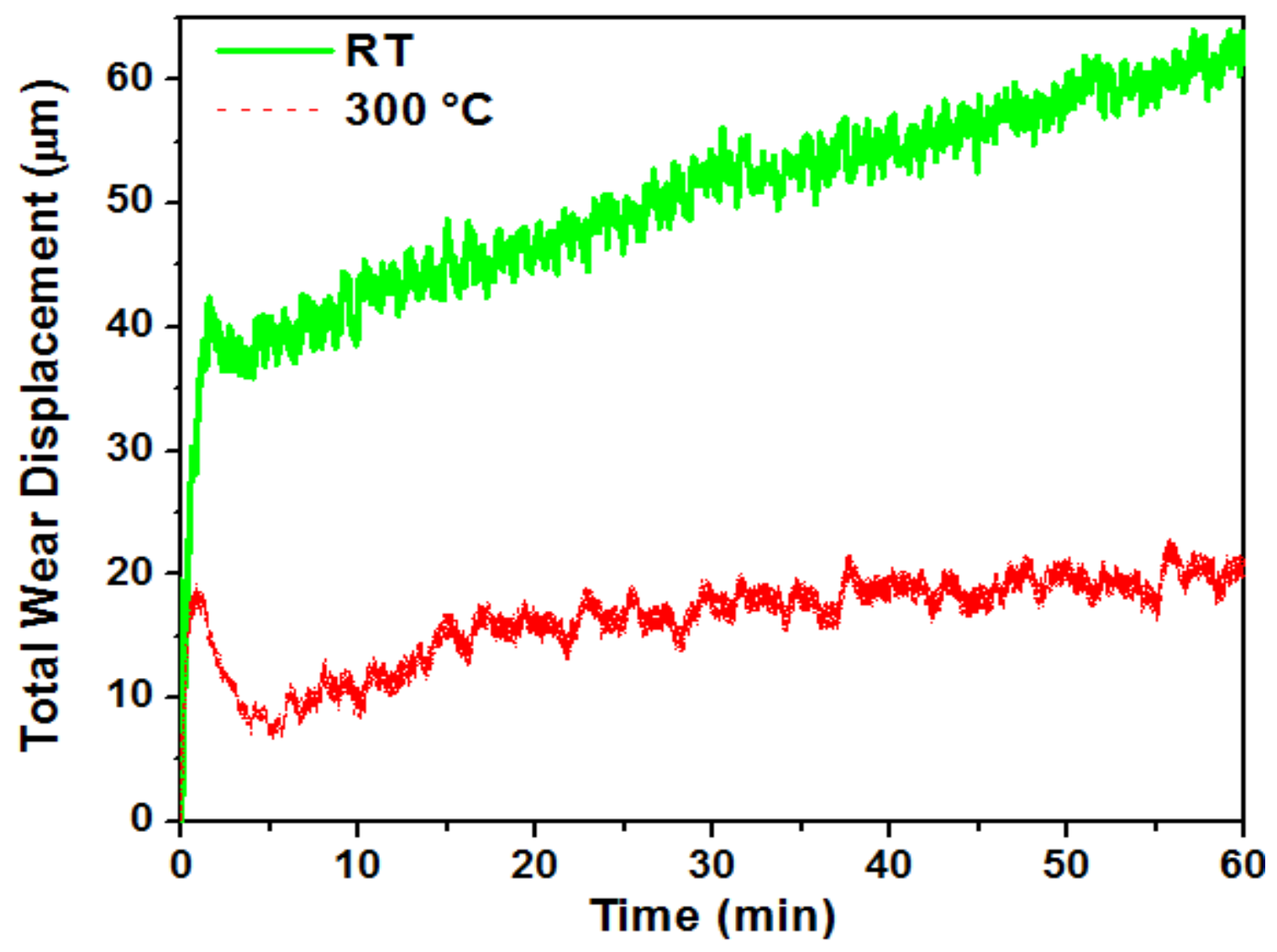

Figure 8: Total wear displacement of WC-Co coating during RT and $300{ }^{\circ} \mathrm{C}$ wear test. Total wear displacement is dependent on both wear of the coating and that of the countersurface ball. A reversal in displacement is due to tribolayer formation. Negative displacement change occurs earlier and to a greater extent at $300 \mathrm{C}$, indicating tribolayer forms more rapidly and is thicker than during $R T$ test.

at a lower rate. During the $300{ }^{\circ} \mathrm{C}$ test, the wear displacement reached a plateau at around 40 min, while for the RT test, the steady rise in wear displacement continued.

Similar trends in total wear displacement were seen in the WC-Co-ND sample (not shown) as both samples appear to have equivalent tribolayer formation at $300{ }^{\circ} \mathrm{C}$. The lack of a more significant tribolayer formation during $300{ }^{\circ} \mathrm{C}$ tests in WC-Co-ND samples is evidence that the ND was no longer having a significant impact on the wear behavior. The evolution of phases, particularly of the ND particles themselves, therefore, had an impact on 
the wear behavior. Specifically, the ND was no longer providing a significant increase in thermal conductivity because significant degradation of the diamond phase occurred at 300 ${ }^{\circ} \mathrm{C}$, as indicated by XPS spectra (Fig. 7b). The degradation of the ND also had additional adverse effects on the composite coatings. The ND was believed to provide some strengthening, particularly to the cobalt matrix, as observed in other metal matrices reinforced with ND [21, 26, 27]. The WC-Co-ND coating had a higher porosity than the WC-Co coating, although their microhardness values were the same (Table 1). The NDinduced strengthening likely compensated for the higher porosity of the coating. However, after the degradation of $\mathrm{ND}$ at $300{ }^{\circ} \mathrm{C}$ the microhardness of the WC-Co-ND coating was lower. Due to the way the composite powder was processed, ND particles were mostly present on the surface of the particles, which then became the splat boundaries. The increased delamination in the WC-Co-ND sample at $300{ }^{\circ} \mathrm{C}$, Fig. 5d, suggests that splat interfaces have been degraded, thereby facilitating the delamination/pull-out of entire splats. The lower wear resistance of the composite coating relative to the unreinforced sample at $300{ }^{\circ} \mathrm{C}$ is attributed primarily to higher porosity and lower hardness, giving higher penetration depth of the counter-surface into the coating and less resistance to abrasion caused by debris particles.

The elevated temperature wear resistance of both coatings benefitted from the phase changes that occurred in the cobalt binder at $300{ }^{\circ} \mathrm{C}$. XRD (Fig. 9) indicate that the cobalt binder in both coatings becomes amorphous in nature as shown by significant peak broadening and loss of intensity of the primary cobalt peak at $\sim 43^{\circ}$. Some of the cobalt binder is also lost in the formation of the ternary carbide $\mathrm{W}_{6} \mathrm{Co}_{6} \mathrm{C}$. Although no increase in hardness was seen, the replacement of the ductile Co metal with ternary carbides and an 
amorphous Co phase would lead to a localized increase in hardness [31, 40], and as long as the wear response does not become brittle, the increased hardness is favorable as it reduces penetration depth.

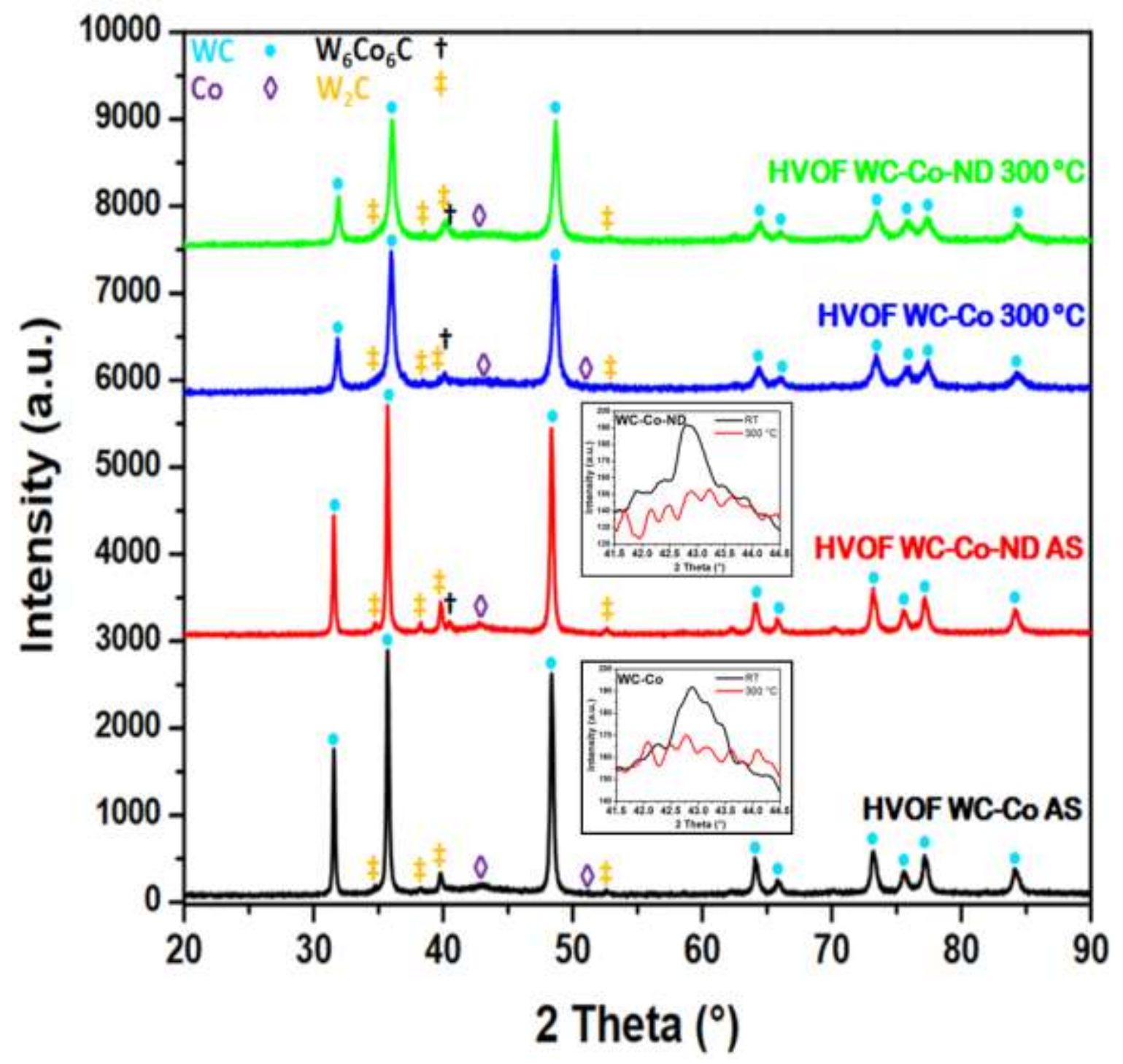

Figure 9: X-Ray diffraction (XRD) patterns of HVOF as-sprayed (AS) coatings and HVOF coatings after $300^{\circ} \mathrm{C}$ wear tests. Insets provide higher resolution plots of Co peaks at $43^{\circ}$.

\subsection{Wear Behavior of Plasma Sprayed Coatings}




\subsubsection{Wear Performance and Mechanisms}

It can be seen that at RT, the WC-Co-ND sample a mean wear volume that was $13 \%$ lower than the mean wear volume in the WC-Co sample (Fig. 10). As with the HVOF samples, at $300{ }^{\circ} \mathrm{C}$,
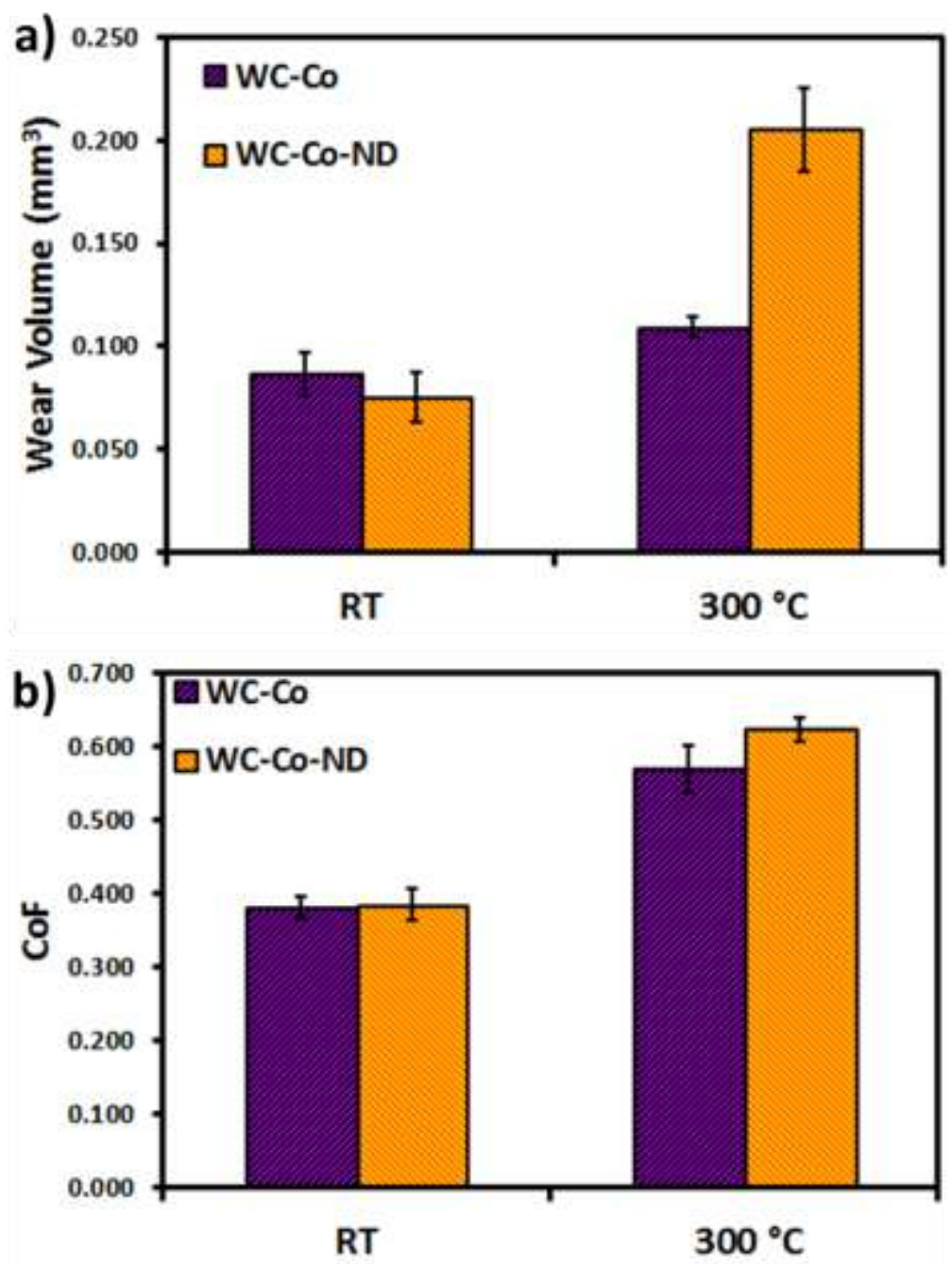

Figure 10: Room temperature and elevated temperature wear study results of coatings, a) Wear volume of APS coatings, b) Coefficient of friction (CoF) of APS coatings. 
the composite coating has poorer wear resistance compared to the unreinforced WC-Co sample. The mean wear volume of the WC-Co-ND coating was $88 \%$ greater than the WCCo coating, (Fig. 10a). However, in contrast to the HVOF coatings, the wear resistance of the APS coatings decreased when temperature was increased. While the CoF of both coatings were similar at RT, the $\mathrm{CoF}$ of the WC-Co-ND was higher than the WC-Co coating. The $\mathrm{CoF}$ of both coatings at $300{ }^{\circ} \mathrm{C}$ was higher than that of the RT test, (Fig. 10).

The wear mechanisms of the APS coatings can be understood from the SEM micrographs of the wear tracks (Fig. 11). Fig. 11a and b show that wear was characterized primarily by moderate abrasion and delamination; however, cracking was also seen throughout the sample, indicating the onset of a brittle wear response. Dark regions in both coatings indicate the presence of a tribolayer, which was once again seen to be more prominent in the WC-Co-ND composite coating. The inset of Fig. 11a shows an EDS map that confirms the presence of a silicon-rich oxide layer (silica) in the coating. Quantitative EDS and XPS analysis (not shown) confirmed that the formed tribolayer was $\mathrm{SiO}_{2}$ as previously confirmed in the HVOF sprayed coatings. The inset of Fig. 11a shows that cracking occurred through both the tribolayer and the surrounding WC-Co material. Cracks were observed to propagate primarily through the cobalt-rich binder. The inset of Fig. 11b shows that localized severe abrasion took place; deep cutting lines due to the reciprocating motion of carbide particles during the dry sliding wear test were observed. The carbide particles appeared to still be embedded in the matrix, indicating that severe abrasion was avoided throughout the coating as carbide particle induced abrasion remained localized. The deep cutting lines were not accompanied by cracking, indicating that the cobalt binder was still retaining its ductility. The morphological features in both APS coatings were similar, 

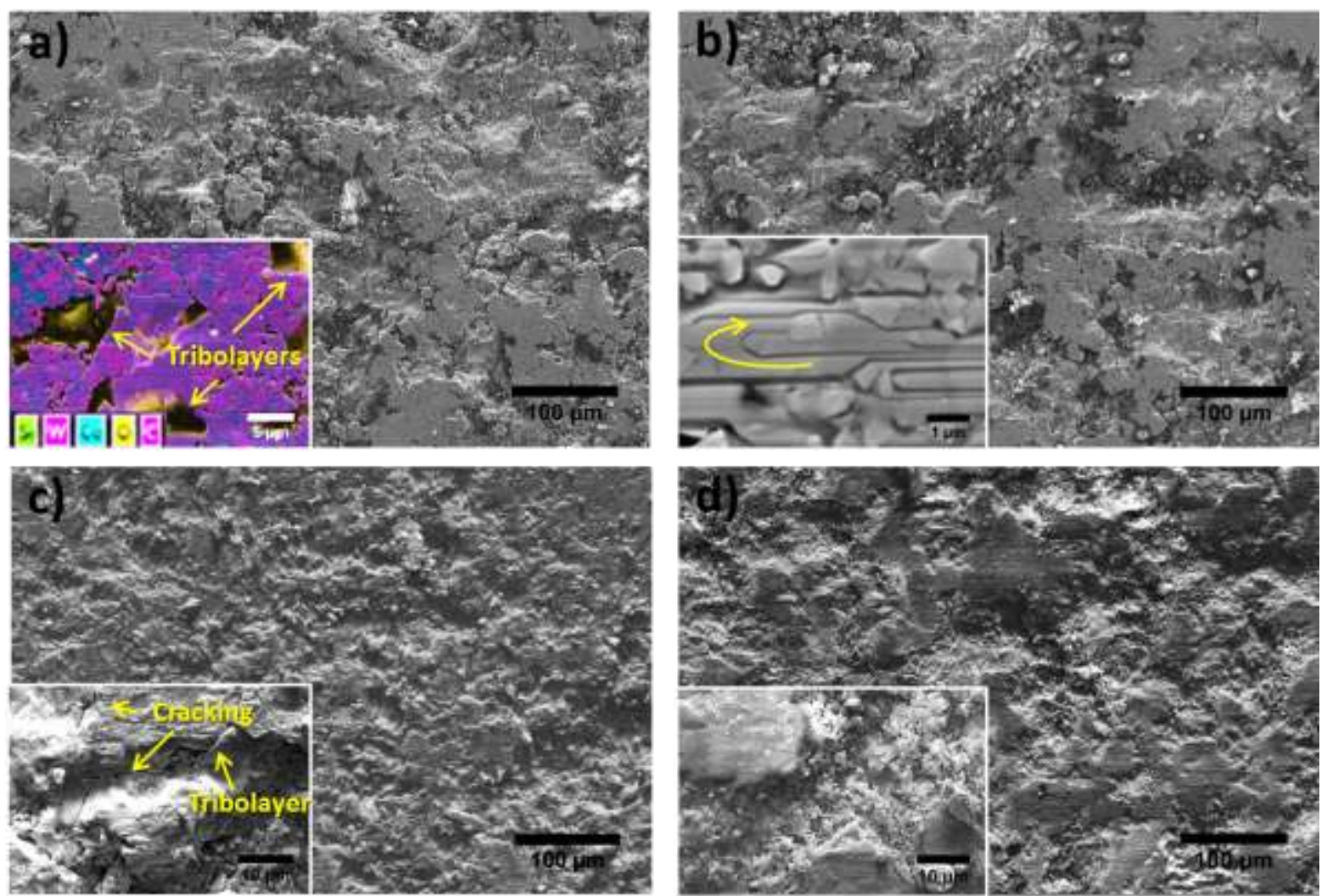

Figure 11: a) SEM (SE) of APS WC-Co wear track after RT wear test, Inset: EDS confirming presence of $\mathrm{SiO}_{2}$ tribolayers. b) SEM (SE) of APS WC-Co-ND wear track after RT wear test. Inset: loose carbide particles act as third body abrasives, leading to deep cutting lines throughout surface. The arrow emphasizes the reciprocating motion of carbide particles, c) SEM (SE) of APS WC-Co wear track after $300^{\circ} C$ wear test. Inset: deep cracks seen throughout wear tracks, and d) SEM (SE) of APS WC-Co-ND wear track after $300{ }^{\circ} \mathrm{C}$ wear test. Inset: fracturing occurs throughout sample leading to loose carbide particles throughout.

(Fig. 11a-b). The enhanced wear resistance of the WC-Co-ND composite coating was attributed to the increased formation of the protective tribolayer. 
The wear tracks of the coatings after the $300{ }^{\circ} \mathrm{C}$ wear test demonstrated that the wear had become more severe and was dominated by severe abrasion and brittle wear. The inset of Fig. 11c shows that large cracks were prominent throughout the coatings; these cracks can facilitate delamination or lead to fracture, which occurred throughout the coating. Debris particles were seen throughout the coating surface and in some cases, the debris particle size was about $10-20 \mu \mathrm{m}$, which was indicative of entire splats becoming delaminated. The inset of Fig. 11d shows that in the WC-Co-ND coating, delaminated or fractured regions were accompanied by significant amounts of fine particle debris, which appeared to be individual carbide grains, indicating that fracture had occurred in the embrittled Co-rich binder. Loose carbide particles led to severe abrasion, as particles were effectively acting as abrasive media, e.g. third-body abrasion. The silica tribolayers were greatly reduced in the $300{ }^{\circ} \mathrm{C}$ wear tests, which coupled with a brittle wear response resulted in the decreased wear resistance at $300{ }^{\circ} \mathrm{C}$ in both coatings. In addition, the composite coating had severe abrasion induced by loose carbide particles, thereby leading to poorer wear resistance than the WCCo coating.

\subsubsection{Phase Evolution and Tribolayer Effects}

Fig. 12 presents the XPS spectra of the plasma sprayed WC-Co-ND wear tracks at RT and $300{ }^{\circ} \mathrm{C}$. The $s p^{3}$ carbon content was $63 \%$ after the RT test, which was higher than in the as-sprayed condition. This indicates that there is a range of $s p^{3}$ content throughout the APS coating, unlike in the HVOF composite coating, which showed equivalent $s p^{3}$ contents in both the as-sprayed condition and post RT wear test. The retention of the diamond phase, 

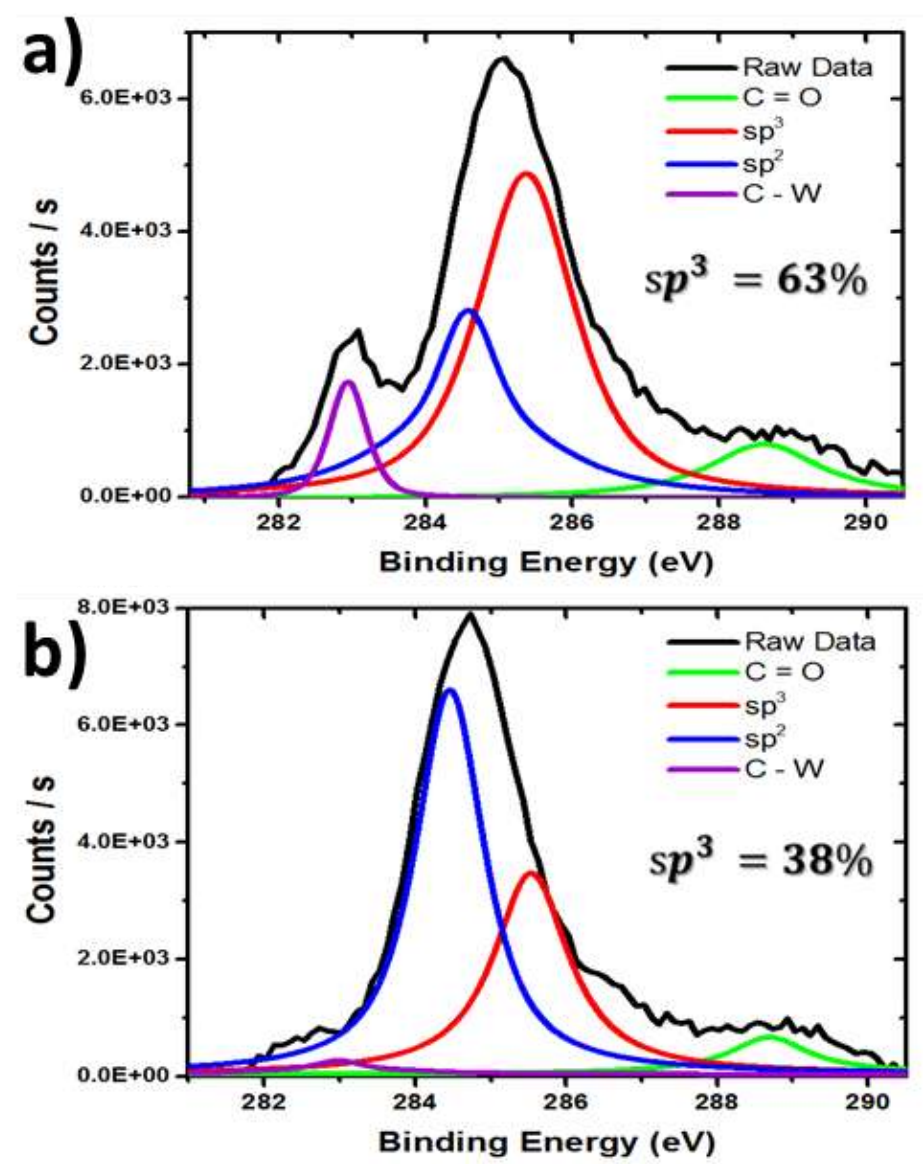

Figure 12: Deconvoluted X-ray photoelectron spectra of a) APS WC-Co-ND wear track after RT wear test, and b) APS WC-Co-ND wear track after $300{ }^{\circ} \mathrm{C}$ wear test. sp $^{3} \%$ denotes percentage of carbon-carbon bonds that are $\mathrm{sp}^{3}$ in nature.

as well as the lower porosity in the plasma sprayed WC-Co-ND coating and the increased protective tribolayer in the composite coating led to enhanced wear resistance in the composite coating relative to the unreinforced WC-Co.

At $300{ }^{\circ} \mathrm{C}$, the XPS spectra in Fig. $12 \mathrm{~b}$ indicated that the diamond phase had become significantly degraded, as the $s p^{3}$ content had dropped to $38 \%$. This decrease in the diamond phase likely led to the slightly lower hardness in the composite coating. The hardness of the plasma sprayed WC-Co coating increased slightly after the $300{ }^{\circ} \mathrm{C}$ wear test. This is due to 
the formation of additional carbides and the embrittlement of the cobalt binder. XRD patterns (Fig. 13) show that $\mathrm{W}_{6} \mathrm{C}_{6} \mathrm{C}$ peaks tended to broaden and have higher relative intensities after the wear tests at $300{ }^{\circ} \mathrm{C}$. The cobalt peaks also

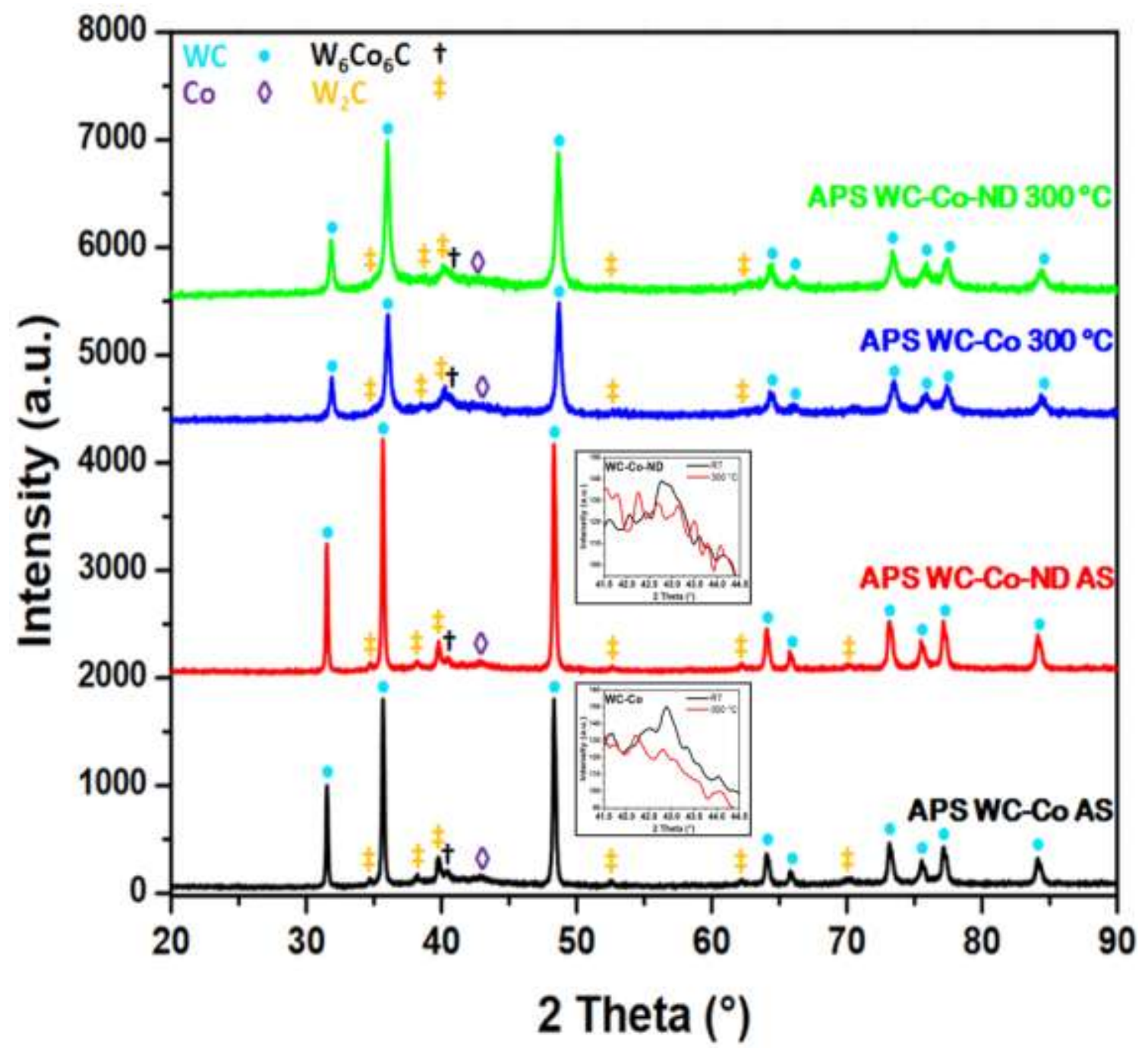

Figure 13: X-Ray diffraction (XRD) patterns of APS as-sprayed (AS) coatings and APS coatings after $300{ }^{\circ} \mathrm{C}$ wear tests. Insets provide higher resolution plots of Co peaks at $43{ }^{\circ}$.

became diffuse and less intense, indicating that the cobalt binder was becoming amorphous and being consumed to form ternary carbides. The formation of additional carbides and the 
amorphization of the cobalt phase also occurred in the WC-Co-ND sample. However, this did not translate into an increase in hardness because of the simultaneous loss in diamond content.

The introduction of harder and more brittle phases is the primary reason why the wear response becomes more brittle at $300{ }^{\circ} \mathrm{C}$ in both coatings. The harder phases were not beneficial as they were in the HVOF coatings, because the wear mechanism was not the same. The loss of ductility was critical as it exacerbated an already brittle wear response, which led to more intense crack propagation, and increased wear as material was fracturing, and entire splats were becoming delaminated. The occurrence of severe wear inhibited the formation of the protective silica tribolayer due to the constant fracturing and removal of material. No sign of significant tribolayer formation was observed in the $300{ }^{\circ} \mathrm{C}$ wear tests. In addition, the tribolayers that did form were not beneficial as at RT wear, because they were brittle and also fractured. In summary, the simultaneous loss of ductility and the absence of a protective tribolayer resulted in both of the plasma sprayed coatings having poorer wear resistance at $300{ }^{\circ} \mathrm{C}$ than at RT.

The primary difference between the WC-Co and the WC-Co-ND coatings after testing at $300{ }^{\circ} \mathrm{C}$ was the presence of fine carbide debris seen throughout the composite coating. XPS spectra (Fig. 12) show that the C - W peaks were greatly diminished after the $300{ }^{\circ} \mathrm{C}$ wear tests. Substantial amounts of the carbide phase became debris particles, making it difficult to get a significant signal. The $\mathrm{C}-\mathrm{W}$ peak was not seen in the as-sprayed condition because the carbide grains were embedded in the cobalt binder. The $\mathrm{C}-\mathrm{W}$ peaks in the APS samples were in sharp contrast to those in the HVOF samples, (Fig. 7). In the HVOF samples, the wear mechanism consisted of mild abrasion and delamination, which 
led to preferential wear of the cobalt binder, thereby resulting in a significant amount of exposed WC particles. It is postulated that the loss of the diamond phase in the APS coatings led to localized porosity and weakened interfaces between carbide particles as well as between splat boundaries that allowed pullout of carbides and splats, leading to increased amounts of loose carbide debris. These debris particles exacerbated wear by serving as third body abrasives. The poorer wear performance of the composite coating at $300{ }^{\circ} \mathrm{C}$ relative to the WC-Co coating is primarily attributed to the increase in carbide particle debris.

It should be noted that the variations in hardness and wear behavior observed here may possibly be influenced by residual stresses in the coatings. In particular, the incorporation of NDs could lead to additional residual stresses because of the CTE mismatch with WC-Co. ND particles within WC can induce compressive residual stresses that enhance fracture strength, as is known to occur in $\mathrm{SiC}$ nanoparticle reinforced $\mathrm{Al}_{2} \mathrm{O}_{3}$ composites [59, 60]. However, high amounts of nanoparticles (greater than 6 vol.\%) have been shown to induce tensile stresses that promote fracture [61, 62]. ND-induced residual stresses in the Co binder could lead to localized hardening that would enhance wear resistance [63]. Previous work on nanoparticle reinforced metal matrix composites has demonstrated that residual stresses are intensified when the reinforcement particle size decreases [64]. However, if residual stresses are too great, they could facilitate fracture within the Co binder [63]. Residual stresses would be most significant in the plasma sprayed coatings due to the higher temperatures involved, and during elevated temperature wear tests, however, the precise measurement of residual stresses is beyond the scope of the present study.

\subsection{CONCLUSIONS}


WC-Co-ND coatings as well as unreinforced equivalents were fabricated in order to investigate the effects of nanodiamonds on the dry sliding wear behavior of WC-Co based composites, at ambient and elevated temperature conditions. The primary findings are summarized as follows:

1) High velocity oxygen fuel spraying (HVOF) and air plasma spraying (APS) was successfully utilized to fabricate WC-Co/nanodiamond coatings; both spray techniques enabled the metastable nanodiamond phase to be deposited with only a modest reduction in the $s p^{3}$ carbon content.

2) The addition of nanodiamonds was seen to enhance the mean room temperature wear resistance by $8.5 \%$ and $13 \%$ in the HVOF and APS coatings, respectively, although some overlap in wear volume values is observed. The excellent thermal conductivity of diamonds enhanced heat transfer to the coatings, which promoted the tribochemical reaction that led to the formation of a protective $\mathrm{SiO}_{2}$ tribolayer.

3) At $300{ }^{\circ} \mathrm{C}$ the nanodiamond phase was degraded in both the HVOF and the APS coatings, which resulted in the wear resistance of the WC-Co-ND coating being lower than that of the respective WC-Co coating.

4) In the HVOF sprayed coatings, lower hardness and weak interfaces, together with the higher porosity of the composite coating, led to increased abrasion and delamination at $300{ }^{\circ} \mathrm{C}$. In the APS coatings, weak interfaces in the composite coating led to more severe brittle wear and the formation of fine carbide debris particles that allowed severe three-body abrasion. 
This study demonstrated the potential of nanodiamond as a reinforcement phase for enhancing dry sliding wear resistance of thermally sprayed WC-Co coatings at room temperature. Elevated temperature dry sliding wear testing gave worse wear performance of WC-Co-ND composite coatings, due to the relative instability of nanodiamond under higher temperature conditions.

\section{Acknowledgements}

AN acknowledges support from the National Science Foundation (NSF) East Asia and Pacific Summer Institutes (EAPSI) program, Award \# 1513669; and from UC Davis through the Eugene Cota-Robles Fellowship. This work was supported by the National Research Foundation of Korea (NRF) grant funded by the Korea Government (MSIP) (No. 20100018289). Authors acknowledge Mahdi Khadem and Anle Yu at the Center for Nano-Wear at Yonsei University for assistance with wear testing and XPS characterization.

\section{References}

[1] M. A. Rafiee, J. Rafiee, Z. Wong, H. Song, Z.-Z. Yu, N. Koratkar, Enhanced Mechanical Properties of Nanocomposites at Low Graphene Content, ACS Nano 3 (2009) 3884-3890.

[2] R. Agrawal, A. Nieto, H. Chen, M. Mora, A. Agarwal, Nanoscale Damping Characteristics of Boron Nitride Nanotubes and Carbon Nanotubes Reinforced Polymer Composites, ACS Appl. Mater. Interfaces 5 (2013) 12052-12057.

[3] B. H. Ryu, A. J. Barthel, H. J. Kim, H. D. Lee, O. V. Penkov, S. H. Kim, D. E. Kim, Tribological Properties of Carbon Nanotube-Polyethylene Oxide Composite Coatings, Compos. Sci. Technol. 101 (2014) 102-109.

[4] O. V. Penkov, H. J. Kim, H. J. Kim, D. E. Kim, Tribology of Graphene: A Review, Int. J. Precis. Eng. Man. 15 (2014) 577-585.

[5] S.R. Bakshi, D. Lahiri, A. Agarwal, Carbon nanotube reinforced metal matrix composites - a review, Int. Mater. Rev. 55 (2010) 41-64. 
[6] D. E. Kim, C. L. Kim, H. J. Kim, A Novel Approach to Wear Reduction of Microcomponents by Synthesis of Carbon nanotube-Silver Composite Coating, CIRP Ann-Manuf. Techn. 60 (2011) 599-602.

[7] M. Rashad, F. Pan, D. Lin, M. Asif, High temperature mechanical behavior of AZ61 magnesium alloy reinforced with graphene nanoplatelets, Mater. Design 89 (2016) 12421250.

[8] A.K. Keshri, A. Agarwal, Wear Behavior of Plasma-Sprayed Carbon NanotubeReinforced Aluminum Oxide Coating in Marine and High-Temperature Environments, J. Therm. Spray Techn. 20 (2011) 1217-1230.

[9] A. Nieto, D. Lahiri, A. Agarwal, Synthesis and properties of bulk graphene nanoplatelets consolidated by spark plasma sintering, Carbon 50 (2012) 4068-4077.

[10] A. Nieto, J.M. Zhao, Y.H. Han, K.H. Hwang, J.M. Schoenung, Microscale Tribological Behavior and In Vitro Biocompatibility of Graphene Nanoplatelet Reinforced Alumina, J. of Mech. Behav. Biomed. 61 (2016) 122-134

[11] S. Osswald, G. Yushin, V. Mochalin, S.O. Kucheyev, Y. Gogotsi, Control of $\mathrm{sp}^{2} / \mathrm{sp}^{3}$ Carbon Ratio and Surface Chemistry of Nanodiamond Powders by Selective Oxidation in Air, J. Am. Chem. Soc. 128 (2006) 11635-11642

[12] V.N. Mochalin, O. Shenderova, D. Ho, Y. Gogotsi, The properties and applications of nanodiammonds, Nat. Nanotechnol. 7 (2012) 11-23.

[13] L. Fang, H. Ohfuji, T. Irifune, A Novel Technique for the Synthesis of Nanodiamond Powder, J. Nanomater. (2013) 201845.

[14] V. Pinchot, B. Risse, F. Schnell, J. Mary, D. Spitzer, Understanding ultrafine nanodiamond formation using nanostructured explosives, Sci. Rep. 3 (2013) 2159.

[15] V.V. Danilenko, Specific Features of Synthesis of Detonation Nanodiamonds, Combustion, Explosion, and Shock Waves 41 (2005) 577-588.

[16] A.P. Chernyshev, L.A. Lukyanchikov, N.Z. Lyakhov, E.R. Pruuel, M.A. Sheromov, K.A. Ten, V.M. Titov, B.P. Tolochko, I.L. Zhogin, P.I. Zubkov, Physical-chemical model of nanodiamond formation at explosion, Nucl. Instrum. Meth. A 575 (2007) 72-74

[17] V.M. Titov, B.P. Tolochko, K.A. Ten, L.A. Lukyanchikov, E.R. Pruuel, Where and when are nanodiamonds formed under explosion?, Diam. Relat.Mater. 16 (2007) 2009-2013. [18] V.Y. Dolmatov, On the Mechanism of Detonation Nanodiamond Synthesis, J. Superhard Mater. 30 (2008) 233-240. 
[19] G.S. Bobrovnitchii, A.L.D. Skury, S.N. Monteiro, R.C. Tardim, Effect of Nanodiamond Addition on the Mechanical Properties of Polycrystalline Metallic and Polymeric Composites, Mater. Sci. Forum 660-661 (2010) 848-853.

[20] J. He, N. Zhao, C. Shi, X. Du, J. Li, P. Nash, Reinforcing copper matrix composites through molecular-level mixing of functionalized nanodiamond by co-deposition route, Mat. Sci. Eng. A-Struct. 490 (2008) 293-299.

[21] V. Livramento, J.B. Correia, N. Shohoji, E. Osawa, Nanodiamond as effective reinforcing component for nano-copper, Diam. Relat. Mater. 16 (2007) 202-204.

[22] K. Hanada, K. Yamamoto, T. Taguchi, E. Osawa, M. Inakuma, V. Livramento, J.B. Correia, N. Shohoji, Diam. Relat. Mater. 16 (2007) 2054-2057.

[23] H. Kaftelen, M.L. Ovecoglu, Microstructural characterization and wear properties of ultra-dispersed nanodiamond (UDD) reinforced Al matrix composites fabricated by ballmilling and sintering, J. Compos. Mater. 46 (2012) 1521-1534.

[24] D.J. Woo, F.C. Heer, L.N. Brewer, J.P. Hooper, S. Osswald, Synthesis of nanodiamond-reinforced aluminum metal matrix composites using cold-spray deposition, Carbon 86 (2015) 15-25.

[25] H. Kwon, G.-G. Lee, S.-G. Kim, B.-W. Lee, W.-C. Seo, Mechanical properties of nanodiamond and multi-walled carbon nanotubes dual-reinforced aluminum matrix composite materials, Mat. Sci. Eng. A-Struct. 632 (2015) 72-77.

[26] D.J. Woo, B. Sneed, F. Peerally, F.C. Heer, L.N. Brewer, J.P. Hooper, S. Osswald, Synthesis of nanodiamond-reinforced aluminum metal composite powders and coatings using high-energy ball milling and cold spray, Carbon 63 (2013) 404-415.

[27] M. Bao, C. Zhang, D. Lahiri, A. Agarwal, The Tribological Behavior of PlasmaSprayed Al-Si Composite Coatings Reinforced with Nanodiamond, JOM 64 (2012) 702708.

[28] V.A. Popov, E. V. Shelekhov, E. Vershinina, Influence of Reinforcing Nonagglomerated Nanodiamond Particles on Metal Matrix Nanocomposite Structure Stability in the Course of Heating, Eur. J. of Inorg. Chem. (2015), DOI:

10.1002/ejic.201501149

[29] K. Yamamoto, T. Taguchi, K. Hanada, E. Osawa, M. Inakuma, V. Livramento, J.B. Correia, N. Shohoji, TEM Studies of Nanocarbons and Nanodiamonds (ND): Mechanical milling of ND and Cu, Diam. Relat. Mater. 16 (2007) 2058-2062. 
[30] Y. Qiao, Y. Liu, T.E. Fischer, Sliding and Abrasive Wear Resistance of ThermalSprayed WC-Co Coatings, J. Therm. Spray Technol. 118 (2001) 118-125.

[31] I. Konyashin, F. Lachmann, B. Ries, A.A. Mazilkin, B.B. Straumal, C. Kubel, L. Llanes, B. Baretzky, Strengthening zones in the Co matrix of WC-Co cemented carbides, Scripta Mater. 83 (2014) 17-20.

[32] S.C. Tjong, Novel Nanoparticle-Reinforced Metal Matrix Composites with Enhanced Mechanical Properties, Adv. Eng. Mater. 9 (2007) 639-652.

[33] Y. Yang, J. Lan, X. Li, Study on bulk aluminum matrix nano-composite fabricated by ultrasonic dispersion of nano-sized $\mathrm{SiC}$ particles in molten aluminum alloy, Mat. Sci. Eng. A-Struct 380 (2004) 378-383.

[34] P.S. Babu, B. Basu, G. Sundararajan, Abrasive wear behavior of detonation sprayed WC-12Co coatings: Influence of decarburization and abrasive characteristics, Wear 268 (2010) 1387-1399.

[35] P.S. Babu, B. Basu, G. Sundararajan, Processing-structure-property correlation and decarburization phenomenon in detonation sprayed WC-12Co coatings, Acta Mater. 56 (2008) 5012-5026.

[36] P.H. Shipway, D.G. McCartney, T. Sudaprasert, Sliding wear behavior of conventional and nanostructured HVOF sprayed WC-Co coatings, Wear 259 (2005) 820-827.

[37] Y. Zhu, K. Yukimura, C. Ding, P. Zhang, Tribological properties of nanostructured and conventional WC-Co coatings deposited by plasma spraying, Thin Solid Films 388 (2001) 277-282.

[38] D.A. Stewart, P.H. Shipway, D.G. McCartney, Microstructural evolution in thermally sprayed WC-Co coatings: comparison between nanocomposites and conventional starting powders, Acta Mater. 48 (2000) 1593-1604.

[39] D.A. Stewart, P.H. Shipway, D.G. McCartney, Abrasive wear behaviour of conventional and nanocomposites HVOF-sprayed WC-Co coatings, Wear 225-229 (1999) $789-798$.

[40] H.L.V. Lovelock, Powder/Processing/Structure Relationships in WC-Co Thermal Spray Coatings: A Review of the Published Literature, J. Therm. Spray Technol. 7 (1998) 357373.

[41] L. Gu, J. Huang, C. Xie, Effects of carbon content on microstructure and properties of WC-20Co cemented carbides, Int. J. Refract. Met. H. 42 (2014) 228-232. 
[42] A. Nieto, A. Kumar, D. Lahiri, C. Zhang, S. Seal, A. Agarwal, Oxidation behavior of graphene nanoplatelet reinforced tantalum carbide composites in high temperature plasma flow, Carbon 67 (2014) 398-408.

[43] Z. Geng, S. Li, D.L. Duan, Y. Liu, Wear behavior of WC-Co HVOF coatings at different temperatures in air and argon, Wear 330-331 (2015) 348-353.

[44] G.M. Balamurugan, M. Duraiselvam, V. Anandakrishnan, Comparison of high temperature wear behaviour of plasma sprayed WC-Co coated and hard chromium plated AISI 304 stainless steel, Mater Design 35 (2012) 640-646.

[45] Q. Yang, T. Senda, A. Hirose, Sliding wear behavior of WC-12\% Co coatings at elevated temperatures, Surf. Coat. Tech. 200 (2006) 4208-4212.

[46] X.-Q. Zhao, H.-D. Zhou, J.-M. Chen, Comparative study of the friction and wear behavior of plasma sprayed conventional and nanostructured WC-12\% Co coatings on stainless steel, Mat. Sci. Eng. A-Struct. 431 (2006) 290-297.

[47] Y. Min, M. Akbulut, K. Kristiansen, Y. Golan, J. Israelachvili, The role of interparticle and external forces in nanoparticle assembly, Nat. Mater. 7 (2008) 527-538.

[48] P. Fauchais, A. Vardelle, B. Dussoubs, Quo Vadis Thermal Spraying?, J. Therm. Spray Technol. 10 (2001) 44-66.

[49] L. Wei, P.K. Kuo, R.L. Thomas, Thermal Conductivity of Isotopically Modified Single Crystal Diamond, Phys. Rev. Lett. 70 (1993) 3764-3767.

[50] K. Yoshida, H. Morigami, Thermal properties of diamond/copper composite material, Microelectron. Reliab. 44 (2004) 303-308.

[51] Z. Tan, Z. Li, G. Fan, X. Kai, G. Ji, L. Zhang, D. Zhang, Fabrication of diamond/aluminum composites by vacuum hot pressing: Process optimization and thermal properties, Compos. Part B-Eng. 47 (2013) 173-180.

[52] Z. Tan, Z. Li, G. Fan, X. Kai, G. Ji, L. Zhang, D. Zhang, Diamond/aluminum composites processed by vacuum hot pressing: Microstructure characteristics and thermal properties, Diam. Relat. Mater. 31 (2013) 1-5.

[53] D. Toma, W. Brandl, U. Koster, The Characteristics of Alumina Scales Formed on HVOF-sprayed MCrAlY Coatings, Oxid. Met. 53 (2000) 125-137.

[54] Y.W. Riddle, T.H. Sanders, A study of coarsening, recrystallization, and morphology of microstructure in Al-Sc-(Zr)-(Mg) alloys, Metall. Mater. Trans. A 35A (2004) 341-350. 
[55] P. John, N. Polwart, C.E. Troupe, J.I.B. Wilson, The oxidation of (100) textured diamond, Diam. Relat. Mater. 11 (2002) 861-866.

[56] J. Qian, C. Pantea, J. Huang, T.W. Zerda, Y. Zhao, Graphitization of diamond powders of different sizes at high pressure-high temperature, Carbon 42 (2004) 2691-2697.

[57] H. J. Kim, S. S. Yoo, D. E. Kim, Nano-scale Wear: A Review, Int. J. Precis. Eng. Man. 13 (2012) 1709-1721.

[58] S.I. Raider, R. Flitsch, J.A. Aboaf, W.A. Pliskin, Surface Oxidation of Silicon Nitride Films, J. Electrochem. Soc. 123 (1996) 560-565.

[59] H. Awaji, S.-M. Choi, E. Yagi, Mechanisms of toughening and strengthening in ceramic-based nanocomposites, Mechanics of Materials 34 (2002) 411-422.

[60] G. Pezzotti, W.H. Muller, Strengthening mechanisms in $\mathrm{Al}_{2} \mathrm{O}_{3} / \mathrm{SiC}$ nanocomposites, Computational Materials Science 22 (2001) 155-168.

[61] I. Levin, W.D. Kaplan, D.G. Brandon, A.A. Layyous, Effect of SiC submicrometer particle size and content on fracture toughness of alumina-SiC nanocomposites, J. Am. Ceram. Soc. 78 (1995) 254-256.

[62] Y. Xu, A. Zangvil, A. Kerber, SiC Nanoparticle-Reinforced $\mathrm{Al}_{2} \mathrm{O}_{3}$ Matrix Composites: Role of Intra- and Intergranular Particles, Journal of the European Ceramic Society 17 (1997) 921-928

[63] A. Mazahery, M. Ostadshabani, Investigation on mechanical properties on nano- $\mathrm{Al}_{2} \mathrm{O}_{3}$ reinforced aluminum matrix composites, Journal of Composite Materials 45 (2011) 25792586.

[64] Z. Zhang, D.L. Chen, Contribution of Orowan strengthening effect in particulatereinforced metal matrix nanocomposites, Materials Science \& Engineering A 483-484 (2008) 148-152. 